\begin{tabular}{ccc}
\hline \multicolumn{3}{c}{ ANNALES } \\
UNIVERSITATIS MARIAE CURIE-SKŁODOWSKA \\
LUBLIN - POLONIA \\
VOL. LXVIII, 1-2 & SECTIO AA & 2013 \\
\hline
\end{tabular}

\title{
FT-IR/PAS study of surface EDTA-ZnO interactions
}

\author{
Marcin Kuśmierz ${ }^{\mathrm{a}}$ and Sylwia Pasieczna-Patkowska ${ }^{\mathrm{b}}$ \\ ${ }^{a}$ Department of Environmental Chemistry, \\ ${ }^{b}$ Department of Chemical Technology, \\ Faculty of Chemistry, Maria Curie-Sklodowska University, \\ pl. M. Curie-Skłodowskiej 3, 20-031 Lublin, Poland \\ amarcin.kusmierz@poczta.umcs.lublin.pl
}

The interaction of EDTA disodium salt with zinc oxide was investigated by photoacoustic (PA) FT-IR. It was demonstrated that EDTA-III adsorbs on $\mathrm{ZnO}$, and the process mimics behaviour of EDTA-oxide systems, in which IEPS of oxide catalytic supports is higher than 9. Model of the interaction, described in literature, was discussed.

\section{INTRODUCTION}

Ethylenediaminetetraacetic acid (EDTA) and its sodium salts are often used in preparation of catalysts by double impregnation method (DIM). In the first stage of the preparation a chelating compound (usually disodium EDTA salt) is deposited on a surface of metal oxide, which serves as a support. After drying, so-called "activated carrier" is impregnated with a solution of a catalyst precursor. This method is well suited for preparing supported catalysts characterized with high metallic phase dispersion [1].

Understanding the interactions between EDTA and support oxides is essential for obtaining catalysts with desired properties. Most of the literature data devoted to this preparation technique is focused on EDTA$\mathrm{Al}_{2} \mathrm{O}_{3}$ [2-5], EDTA-AlPO 4 [6] and EDTA-MgO/Al $\mathrm{O}_{3}$ systems [7]. 
Contrary to $\mathrm{SiO}_{2}$ or $\mathrm{Al}_{2} \mathrm{O}_{3}$, zinc oxide is a partially reducible support [8-10] and therefore reduced $\mathrm{Zn}$ may form alloys with main metallic phase. In some cases such binary catalyst performs better than a singlephase one: Iwasa [11] reported that in the reaction of $\mathrm{CO}_{2}$ hydrogenation on $\mathrm{Pd}-\mathrm{Zn} / \mathrm{ZnO}$ catalysts showed higher activities and selectivities towards methanol than pure palladium based ones.

The DIM method facilitates high dispersion of catalyst metallic phase, thus forming alloys is easier. This study focuses on phenomena occurring during the first stage of the process: interactions between EDTA and $\mathrm{ZnO}$.

\section{EXPERIMENTAL}

Two samples of $\mathrm{ZnO}$ (supplied by INS Puławy, Poland) were calcined in air at $823 \mathrm{~K}$ using muffle furnace for 8 hours (sample S8) and 4 hours (sample S4). According to calcination curve supplied by producer this thermal treatment lowered their surface areas to about $5 \mathrm{~m}^{2} / \mathrm{g}$ and $15 \mathrm{~m}^{2} / \mathrm{g}$, respectively. EDTA and it salts strongly chelates metal ions (which charge is at least +2 ). It even may leach them from oxide and hydroxide solids [12-15]. High surface area of metal oxides facilitates this phenomena and in consequence may hinder investigations of EDTA adsorption. In the case when this phenomena would have been observed for S4 samples, strongly calcined S8 samples have been prepared.

Both S8 and S4 samples were divided into subsamples S8H, S8E and S4H, S4E, respectively. Subsamples S8E and S4E were impregnated with $0.1 \mathrm{M}$ EDTA-III (EDTA disodium salt, $\mathrm{Na}_{2} \mathrm{H}_{2} \mathrm{Y}$, supplied by POCh, Gliwice) solution at $343 \mathrm{~K}$ for 20 minutes. For the reference purposes subsamples $\mathrm{S} 8 \mathrm{H}$ and $\mathrm{S} 4 \mathrm{H}$ were treated in the same manner with distilled water. All the subsamples were then dried at $391 \mathrm{~K}$ overnight.

FT-IR/PAS spectra of investigated materials (S8H, S4H, S8E, S4E) were recorded using Bio-Rad spectrometer equipped with MTEC300 photoacoustic detector, over the $4000-400 \mathrm{~cm}^{-1}$ range. The spectra were measured at $\mathrm{RT}$ at $4 \mathrm{~cm}^{-1}$ resolution and normalized by computing the ratio of a sample spectrum to the spectrum of a MTEC carbon black standard. Prior to measurements the PA cell was purged with dry helium for 5 minutes. Interferograms of 512 scans were average for each spectrum. Spectra of untreated $\mathrm{ZnO}$ samples ( 88 and $\mathrm{S} 4$ ) were also recorded. 


\section{RESULTS AND DISCUSSION}

Spectra of S8, S8H and S8E samples are presented in Figure 1. Peaks at $3065,2957,2922$ and $2854 \mathrm{~cm}^{-1}$ (small chart) are characteristic for surface carbon species [18]. Their presence is caused by incomplete removal of graphite, which is used as a grease during production of $\mathrm{ZnO}$ pellets. This implies that flow furnance and oxygen atmosphere should be used, rather than muffle one and air.

Band at $1640 \mathrm{~cm}^{-1}$, present in spectra $\mathrm{S} 8$ and $\mathrm{S} 8 \mathrm{H}$ is ascribed to oxide surface hydroxyl groups. In spectrum S8E this peak is covered by features at 1626 and $1670 \mathrm{~cm}^{-1}$ (very weak shoulder), which can be assigned to $v_{\mathrm{as}}-\mathrm{COO}^{-}$and $-\mathrm{COOH}$ vibrations of EDTA-III carboxyl groups, respectively [16-18]. Bands associated with strong symmetric vibrations of $-\mathrm{COO}^{-}$groups appear at 1400 and $1323 \mathrm{~cm}^{-1}$, and the peak at $1280 \mathrm{~cm}^{-1}$ corresponds to vibrations of $-\mathrm{CH}_{2} \mathrm{COOH}$ chains [16-18].

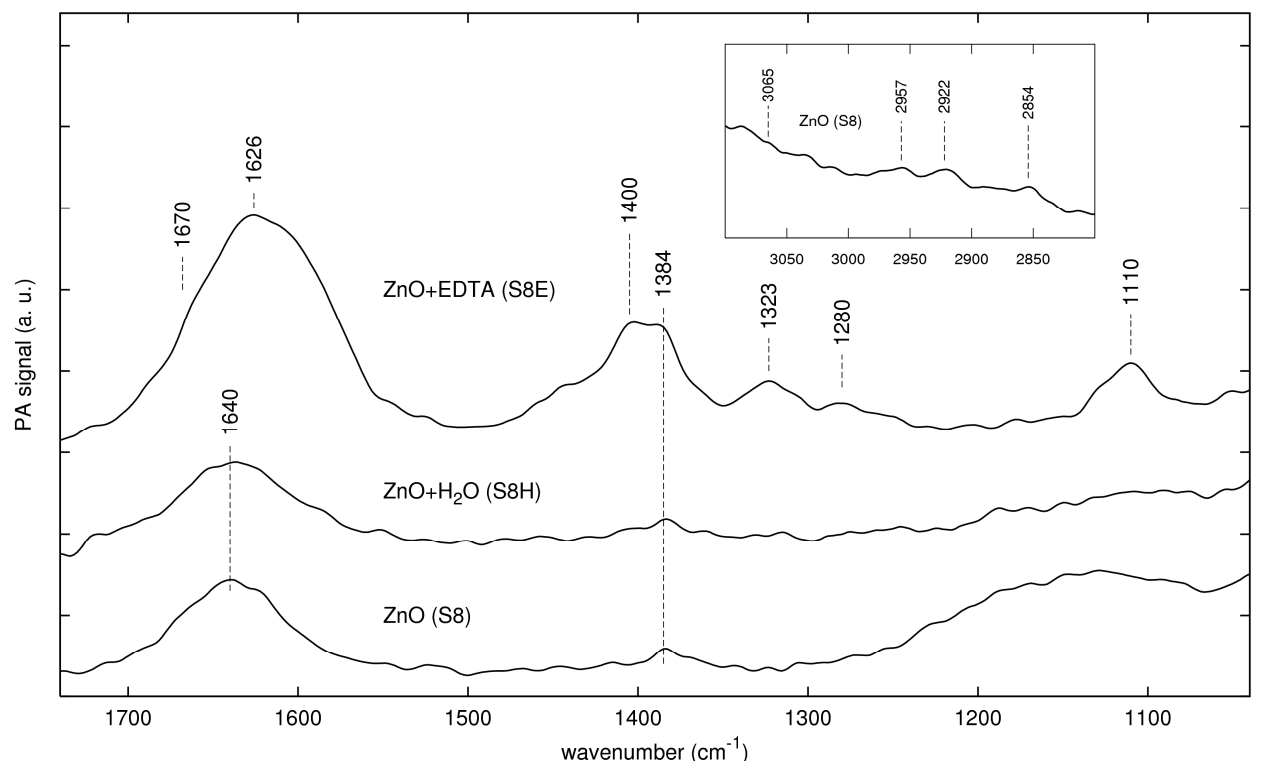

Fig 1. FT-IR/PAS spectra of S8E, S8H and S8 samples.

The presence of EDTA adsorbed on the $\mathrm{ZnO}$ surface is confirmed by relatively intensive band at $1110 \mathrm{~cm}^{-1}$, which is attributed to stretching of C-N bond [16-18]. Spectra of S4, S4H and S4E samples were almost identical to those described above, and therefore they are not shown.

Interactions between adsorbates and metal oxides strongly depends on surface composition of the latter. Hydroxyl groups and their 
distribution are of special importance. In the case of impregnation from water solutions, the population of these species depends on isoelectric point of solid surface (IEPS) and $\mathrm{pH}$ of the solution [19]. Equations describing protonation, deprotonation and state of the oxide surface in water solution are included in papers [20,21]. Their more general form is presented in paper [5], and can be applied to various oxides:

$$
\begin{array}{ll}
\equiv \mathrm{M}-\mathrm{O}^{-} & \mathrm{pH}>\text { IEPS } \\
\equiv \mathrm{M}-\mathrm{OH} & \mathrm{pH} \approx \text { IEPS } \\
\equiv \mathrm{M}-\mathrm{OH}_{2}^{+} & \mathrm{pH}<\text { IEPS }
\end{array}
$$

In publication [5] models of interactions between EDTA disodium salt and various inorganic oxides are shown. For magnesium oxide the proposed reaction is as follows:
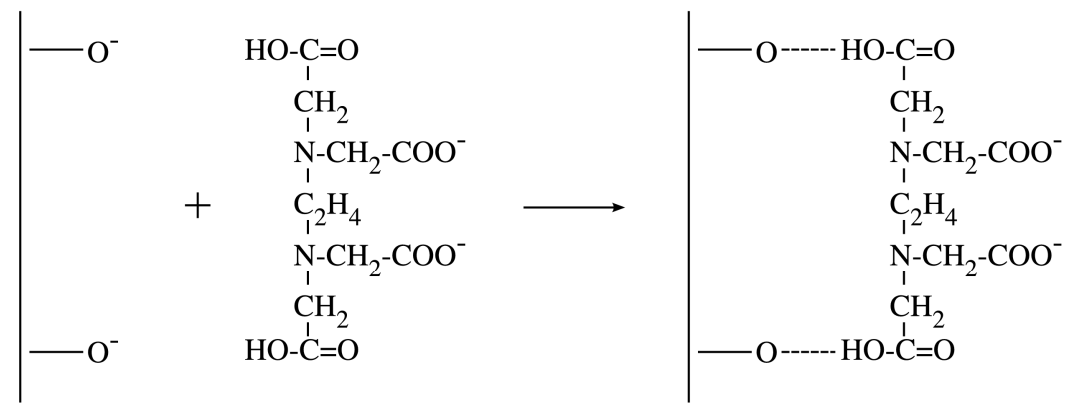

According to scheme (4) EDTA salt interacts with surface $\mathrm{M}-\mathrm{O}^{-}$ species via undissociated carboxyl groups. This view is supported by relative intensity of bands in spectrum included in cited work: peak corresponding to $-\mathrm{COO}^{-}$groups is more intensive than one associated with $-\mathrm{COOH}$ groups.

IEPS values for $\mathrm{MgO}$ and $\mathrm{ZnO}$ are in similar, alkaline range: $\approx 12$. Because $\mathrm{pH}$ of impregnation solution used $(\approx 6)$ was far below this value, according to equation (3) the most numerous surface species were $\mathrm{M}-\mathrm{OH}$ and $\mathrm{M}-\mathrm{OH}^{+}{ }_{2}$ groups. Moreover, if the oxide surface is positively charged it is more likely to happen that EDTA salt will contact with surface via dissociated carboxyl groups, due to electrostatic forces. Higher intensity of the peak at $1626 \mathrm{~cm}^{-1}$, corresponding to asymmetric vibrations of $-\mathrm{COO}^{-}$, in comparison to the peak at $1670 \mathrm{~cm}^{-1}$ (-COOH groups) can be explained by dissociation of adsorbed EDTA carboxyl groups. Scheme 
(5) describes proposed model of EDTA salt adsorption from weakly acidic solution.

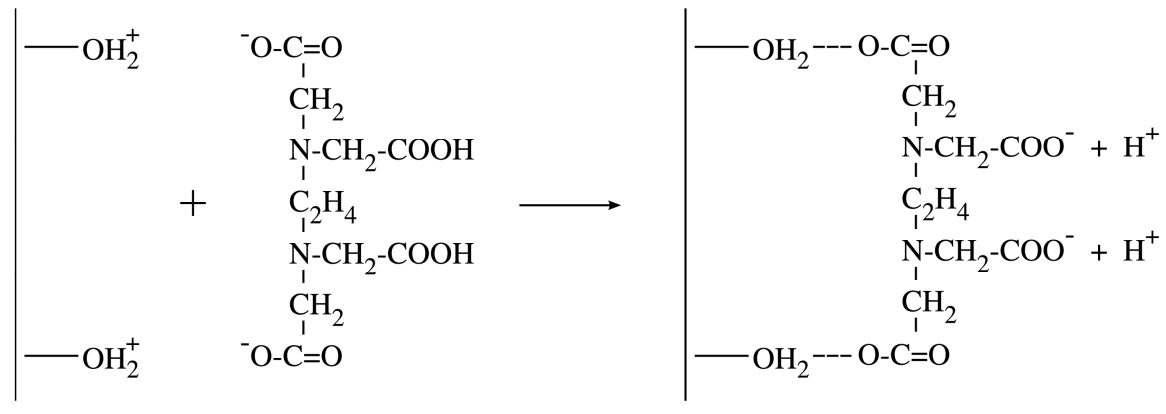

\section{CONCLUSIONS}

It was demonstrated that EDTA-III is adsorbed on zinc oxide surface and it can be assumed, that application of double impregnation method for preparing catalysts supported on $\mathrm{ZnO}$ is possible.

Low $\mathrm{pH}$ (c.a. 6) of impregnation solution in combination with high IEPS of $\mathrm{ZnO}$ suggest, that during the impregnation $-\mathrm{OH}^{+}$groups were most numerous surface species. This suggestion is supported by relatively high intensity of bands at $1640 \mathrm{~cm}^{-1}$ and $1384 \mathrm{~cm}^{-1}$, corresponding to oxide surface hydroxyl groups.

The foregoing statement indicates that EDTA-III adsorbs on surface of zinc oxide mainly via dissociated carboxyl groups. Strong peaks at $1626 \mathrm{~cm}^{-1}$ corresponding to assymetric vibrations of $-\mathrm{COO}^{-}$groups are probably caused by deprotonation of hitherto undissociated EDTA-III carboxyl groups.

\section{REFERENCES}

[1] J. Barcicki, D. Nazimek, React. Kinet. Catal. Lett., 17, 169 (1981).

[2] D. Nazimek, J. Ryczkowski, Appl. Catal., 26, 47 (1986).

[3] J. Ryczkowski, T. Borowiecki, React. Kinet. Catal. Lett., 49, 127 (1993).

[4] T. Shimizu, K. Hiroshima, T. Honma, T. Mochizuki, M. Yamada, Catal. Today, 45, 271 (1998).

[5] J. Ryczkowski, Appl. Surf. Sci., 252, 813 (2005). 
[6] F. M. Bautista, J. M. Campelo, A. Garcia, R. Guardeno, D. Luna, J. M. Marina, J. Catal., 125, 171 (1990).

[7] C. Qi, T. Bai, L. An, React. Kinet. Catal. Lett., 54, 131 (1995).

[8] N. Iwasa, S. Kudo, H. Takahashi, S. Masuda, N. Takezawa, Catal. Lett., 19, 211 (1993).

[9] N. Iwasa, S. Masuda, N. Ogawa, N. Takezawa, Appl. Catal. A, 125, 145 (1995).

[10] N. Iwasa, N. Takezawa, Top. Catal., 22, 215 (2003).

[11] N. Iwasa, H. Suzuki, M. Terashita, M. Arai, N. Takezawa, Catal. Lett., 96, 75 (2004).

[12] E. B. Borghi, A. E. Regazzoni, A. J. G. Maroto, M. A. Blesa, J. Colloid Interface Sci., 130, 299 (1989).

[13] J. A. Rumball, G. D. Richmond, Int. J. Miner. Process, 48, 1 (1996).

[14] J. K. Klewicki, J. J. Morgan, Geochim. Cosmochim. Acta, 63, 3017 (1999).

[15] H. Tamura, N. Ito, M. Kitano, S. Takasaki, Corros. Sci., 43, 1675 (2001).

[16] T. Sawyer, P. J. Paulsen, Int. J. Chem. Soc., 80, 1597 (1958).

[17] R. E. Sievers, J. C. Bailar Jr., Inorg. Chem., 1, 174 (1962).

[18] G. Socrates, Infrared and Raman Characteristic Group Frequencies. Tables and Charts (Wiley, Chichester 2001) p. 132.

[19] G. A. Parks, Chem. Rev., 65, 177 (1965).

[20] U. Olsbye, R. Wendelbo, D. Akporiaye, Appl. Catal. A, 152, 127 (1997).

[21] K. M. Hardiman, C. H. Hsu, T. T. Ying, A. A. Adesina, J. Mol. Catal. A, 239, 41 (2005).

\section{CURRICULA VITAE}

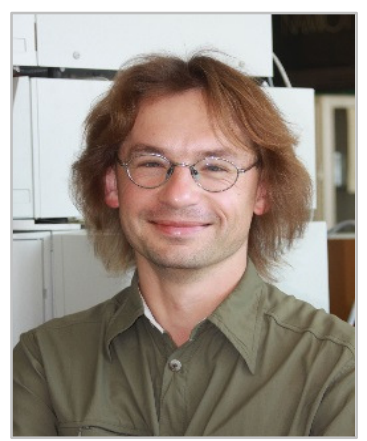

Marcin Kuśmierz born in Lublin (1971). Graduated from Maria Curie-Skłodowska University in Lublin (1997). Received his Ph. D. degree in physical chemistry (2005) from the Maria Curie-Skłodowska University. His main fields of interest are environmental impacts of biochars use and fate and bioavailability of hydrophobic organic pollutants in environment (especially PAHs and o-PAHs). 


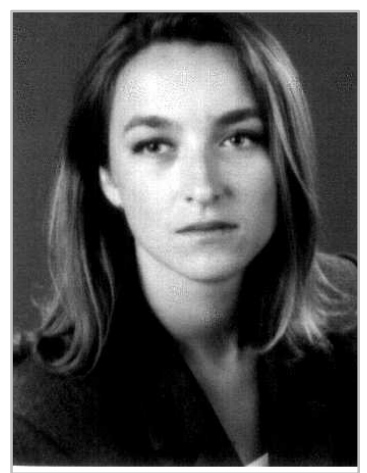

Sylwia Pasieczna-Patkowska was born in Lublin, Poland in 1974. She studied chemistry at the Maria Curie-Skłodowska University, graduated in 1998. Received her Ph.D. (2006) in physical chemistry from the UMCS in Lublin. Since 2007 she is an adjunct at UMCS. She is an author and co-author of 73 articles in sciencetechnical press, the author and co-author of 126 papers and posters at domestic and foreign conferences. Scientific interests: infrared spectroscopy, chemical technology. She is member of Polish Chemical Society (1998- ) and Polish Catalysis Club (1998- ). 